\title{
Graciliano Ramos
}

Recebido: 13.11 .19

e a roda de Maceió*

Wellington Pascoal de Mendonça**

Resumo: Entre as décadas de 1930 e 1940, a inserção e permanência dos escritores em posições vantajosas no incipiente campo literário brasileiro demandava o cumprimento de uma série de exigências, como conseguir editores e avaliações positivas da crítica. Este artigo, ao combinar a análise de correspondências, entrevistas, biografias e críticas literárias, trata dos expedientes que os escritores poderiam mobilizar ao se lançarem na vida literária. Nesse sentido, recupero a trajetória de Graciliano Ramos, sobretudo suas relações com a roda de Maceió - amizade, sociabilidade literária, solidariedade e interesse também - a fim de evidenciar como o escritor valeu-se desse cabedal de relações sociais para levar adiante sua carreira.

Palavras-chave: Graciliano Ramos. Roda de Maceió. Literatura brasileira. Campo literário. Sociologia da cultura.

\section{Graciliano Ramos \\ and the group of intellectuals of Maceió}

Abstract: Between the 1930s and 1940s, the insertion as well as the permanence of writers in advantageous positions in the incipient Brazilian literary field demanded the performing of a series of requirements, such as getting editors and positive reviews of the critic. This article, combining the analysis of correspondence, interviews, biographies and literary criticism, deals with the expedients that writers could mobilize in launching themselves into literary life. In this sense, I recover the trajectory of Graciliano Ramos, especially his relations with the group of intellectuals of Maceió - friendships, literary sociability, solidarity as well interests - in order to show how the writer used this arrange of social relations to carry on his career.

Keywords: Graciliano Ramos. Group of intellectuals of Maceió. Brazilian literature. Literary field. Sociology of culture.

\section{Instâncias de consagração literária e rodas intelectuais}

5

arreiras quase intransponíveis colocavam-se aos escritores que migravam das regiões periféricas para o centro da produção literária quando não dispunham de um cabedal de relações sociais. Entre o fim do século XIX e o início do XX, o acionamento dessas relações mostrava-se indispensável a uma integração bem-sucedida de migrantes junto às rodas literárias do Rio de Janeiro. $O$

\author{
* Este artigo \\ apresenta alguns \\ resultados da \\ minha pesquisa \\ de mestrado, \\ que contou com \\ financiamento da \\ Coordenação de \\ Aperfeiçoamento \\ de Pessoal de Nível \\ Superior (Capes).
** Doutorando em sociologia na Faculdade de Filosofia, Letras e Ciências Humanas da Universidade de São Paulo (USP), onde realizou o mestrado em sociologia e o bacharelado em ciências sociais, São Paulo, SP, Brasil. Orcid: 0000-0003- 2559-2164. $<$ pascoal. mendonca@gmail. com>.


deslocamento era necessário porque as instâncias de consagração - os principais críticos e as editoras, e mesmo a Academia Brasileira de Letras - estavam reunidas na capital do país.

Após a realização da Semana de Arte Moderna em São Paulo, a centralidade da produção deixou de ser uma prerrogativa do Rio de Janeiro, sendo compartilhada com os paulistas, ao menos nos anos de 1920. A década de 1930, na esteira do que ocorrera no decênio anterior, foi marcada por nova revitalização da literatura, e a produção se deslocou por outras regiões do país, criando, assim, polos importantes no Nordeste e no Sul, além de expandir-se no Sudeste (Arruda, 2011). No entanto, ainda que a produção tenha se deslocado por essas regiões, as instâncias de consagração continuavam concentradas no Rio de Janeiro, e a migração ainda era necessária para aqueles que pretendiam ser reconhecidos nacionalmente.

Se nos anos finais do século XIX e iniciais do XX a Academia Brasileira de Letras ocupou um destacado papel para a consagração dos escritores, entre as décadas de 1930 e 1940 os críticos e as editoras figuraram como as principais instâncias legitimadoras. De acordo com Sergio Miceli (2001) e Randal Johnson (1995), num campo literário ainda incipiente, onde um mesmo sujeito exercia, por vezes, as funções de escritor, crítico e editor, o reconhecimento como produtor de literatura legítima - cujas exigências principais não eram comerciais, mas formais e estéticas - era conferido por aquelas instâncias através de sanções positivas que iam paulatinamente emitindo, fossem elas na forma de edição e reedição de livros, ou como artigos favoráveis em jornais e revistas. O acúmulo de ambos no tempo, tomados como recompensas simbólicas, concorria para a eventual consagração, bem entendido, para a inscrição do nome dos escritores no cânone literário.

Nessas disputas, mais uma vez se impuseram com força as rodas intelectuais, que além de darem lastro institucional aos seus integrantes - de conferir a eles o reconhecimento social como escritor, artista etc. -, atuaram no sentido de conseguirem condições vantajosas tanto para a edição dos trabalhos como para a recepção dos mesmos.

\section{A roda de Maceió e a legitimação de Graciliano Ramos}

A trajetória de Graciliano Ramos ilustra bem esse estado de coisas. Antes de se firmar como escritor, experimentara uma frustração quando tentou ingressar numa carreira intelectual no Rio de Janeiro entre 1914 e 1915. Percebeu então que sem uma rede de solidariedade provavelmente experimentaria outro fracasso em sua 
nova investida. Daí a importância das relações que foi constituindo com membros de uma fração da oligarquia de Alagoas, que Ihe arranjaram empregos na administração pública, fazendo-o, inclusive, prefeito de Palmeira dos Índios. Foram esses vínculos que lhe permitiram voltar a Maceió, onde pôde frequentar a roda intelectual que ali se formava na virada dos anos 1920-1930.

Alagoas, entre esses anos, tornou-se um importante centro de produção cultural, sobretudo literária, já que de lá saíram em direção ao Rio de Janeiro a maior parte daqueles que ficariam conhecidos como os romancistas do Nordeste. Este processo, por sua vez, esteve relacionado com a descentralização da produção literária ocorrida nesse segundo momento do movimento modernista. Tendo em vista meus propósitos, a roda de Maceió ganha importância por ter constituído uma rede de sociabilidade e, principalmente, pelo tipo de ação empreendida por seus integrantes no sentido de promoverem-se mutuamente (Sorá, 2010; Silva, 2004).

Graciliano começou a redigir Caetés em torno de 1925, concluindo-o em 1930. Até o início dessa década, permaneceu em Palmeira dos Índios, cidade na qual se dividia entre o comércio, as contribuições para um jornal local e os cargos na administração municipal. Em meados de 1930, assediado pelo multifacetado poeta, crítico, editor e empresário Augusto Frederico Schmidt - e por seu secretário, Rômulo de Almeida -, iniciou as conversas para a edição de seu primeiro romance.

Rio, 17/06/1930.

Meu caro Graciliano.

Só hoje obtive resposta à minha carta de 9 de maio. Já estava pensando que $V$. queria se ver livre dos incômodos de mais uma afeição. Já estaria farto delas...

Hoje Ihe mandei, registrada, uma prova em 2 volumes da simpatia do Tristão de Athayde.

Quem me disse que o Álvaro Paes era seu cunhado, foi um outro admirador seu, que atende pelo nome de Arthur Gaspar Vianna.

Quanto à sua obra, já não lhe direi mais nada além disso. V. conta com os dois maiores críticos do Brasil, Tristão e Agripino; V. obterá um êxito formidável.

Fiquei muito satisfeito com a sua resolução no post scriptum: "Vou publicar os Caetés".

Estou pronto a Ihe prestar a chusma de favores. A Livraria Católica se encarregará, se Ihe convém, da distribuição e reclamo do livro. Espero que V. me diga alguma coisa sobre esta sugestão. Eu sou empregado dessa Livraria, da qual é sócio o Schmidt. [...] 
1. A biografia do escritor (Moraes, 2012: 73-74) apresenta duas versões sobre o caso. Uma delas, de tom anedótico, diz que Augusto Frederico Schmidt teria lido os relatórios "romanceados" de prestação de contas que Graciliano enviara ao governador de Alagoas, o que o fez suspeitar da possibilidade do então prefeito de Palmeira dos Índios ter alguma coisa de cunho literário. Outra, reputada por seu biógrafo como mais pertinente, alude ao fato de Graciliano ter ficado conhecido no Rio de Janeiro por intermédio de Santa Rosa, que migrara para a capital do país visando a carreira artística. Já a existência de um romance teria sido referida por José Américo de Almeida, daí, então, Schmidt ter feito contato com Graciliano.

2. Quanto às relações entre editores, críticos e escritores alguns elementos devem ser destacados. Um deles referese à sociabilidade forjada nas livrarias, caracterizada pela amizade, bem como afinidades ideológicas e estéticas. Outro elemento, derivado desse, é o fato de elas servirem como reduto para grupos diversos de intelectuais. A
Bem, Graciliano, por hoje chega. À sua inteira disposição está o seu amigo de fato.

Rômulo de Almeida

P.S. $[\ldots]$

Sr. Graciliano Ramos.

Pedi licença ao meu amigo e companheiro de trabalho Rômulo para reforçar o pedido dele Rômulo, para que fique a Livraria aqui depositaria do seu romance Caetés.

Estou absolutamente certo do sucesso do seu livro, me autorizando a pensar assim o capítulo que mandou ao Rômulo. A edição deve ser grande. Quem sabe se o sr. não logrará o êxito, de "A Bagaceira", por exemplo.

Saudações

A. F. Schmidt (Arquivo IEB-USP, Fundo Graciliano Ramos, Coleção Correspondência Passiva, código do documento GR-CP-058).

Dois aspectos chamam a atenção nessa correspondência. O primeiro é a forma como a negociação estava ocorrendo, pois Graciliano foi procurado pelo editor, que soubera da existência do livro. Isso é curioso porque, à época, os aspirantes a escritores, principalmente aqueles que estavam distantes dos grandes centros, geralmente procuravam os editores e, quase sempre, com uma "carta de recomendação" de algum padrinho ${ }^{1}$. O outro diz respeito à maneira incisiva como Rômulo e o próprio Schmidt assediam Graciliano a fim de torná-lo mais firme em sua decisão de publicar Caetés. O secretário da editora refere-se à recepção positiva de dois dos principais críticos da década de 1930, Tristão de Athayde (Alceu Amoroso Lima) e Agripino Grieco. Schimdt, por sua vez, fala do sucesso daquele que inaugurara a fase dos romances "regionalistas" do Nordeste, José Américo de Almeida, com seu A bagaceira ${ }^{2}$.

Outras correspondências foram trocadas por Rômulo e Graciliano, e apesar da insistência do editor, bem como do entusiasmo do escritor, a publicação de Caetés foi adiada, provavelmente em razão das dificuldades financeiras enfrentadas pela editora de Augusto Frederico Schmidt. Em carta remetida a Graciliano em 15 de abril de 1931, Rômulo trata dessa questão e do consequente atraso da edição do livro:

O Schimdt vai Ihe mandar os "Caetés" para correção, mas já em provas. Ele vem demorando por causa da crise. De fato, está um buraco o negócio... principalmente de livros (Arquivo IEB-USP, Fundo Graciliano Ramos, Coleção Correspondência Passiva, código do documento GR-CP-063). 
Essa situação fez com que o entusiasmo de Graciliano se revertesse em novo desânimo, pois ele já havia passado por um dissabor quando tentara se inserir nos meios literários do Rio de Janeiro em meados do decênio de 1910. Em carta de 25 de abril de 1931 remetida ao seu cunhado, Luís Augusto de Medeiros, Graciliano deixa claro seu descontentamento:

\section{Luís:}

Recebi tua carta de 16 e depois recebi também uma tapeação do Rômulo. Como te disse, a história do livro acabou. A coisa é esta: eles imaginaram que aquilo era realmente um romance e começaram a elogiá-lo antes do tempo. Quando viram que se tinham enganado, tiveram acanhamento de desdizer-se. Compreendo perfeitamente a situação deles e, para não entrarmos em dificuldades, não toco mais no assunto (Ramos, 2011: 154).

Como naquela ocasião, e sem negligenciar a situação financeira da Livraria Schmidt Editora, o fato de o escritor ainda não contar com um cabedal de relações vantajosas que pudesse mobilizar a seu favor tornava a publicação do livro mais custosa. Dessa maneira, Graciliano o viu permanecer nas gavetas do editor até que passasse a integrar a roda de Maceió, que se formou no início do decênio de 1930, e funcionava como um grupo de sociabilidade restrita. Na avaliação de Rachel de Queiroz:

Éramos grandes amigos, eu, ele, a mulher dele. A gente se frequentava muito. Nesse período em Maceió, por coincidência, Zé Lins morava lá, engraçado. Ele era fiscal de imposto e consumo e morava lá. E o Aurélio Buarque de Holanda também morava lá, era de lá. Era uma roda de tantos que depois vieram para cá! Então a gente tinha um botequim, um café, um ponto chique de Maceió onde a gente se reunia todas as tardes pra tomar um chopinho, um cafezinho, pra conversar. Depois viemos para cá, Alberto Passos Guimarães; Valdemar Cavalcanti, um político; Aurélio Buarque de Holanda, do dicionário; Graciliano; eu; Zé Lins. Nos reunimos em Maceió nesse período (Sorá, 2010: 147).

Nessa entrevista, Rachel aludiu aos "grandes amigos" Graciliano Ramos e Heloísa de Medeiros Ramos, sua esposa, e aos demais companheiros de roda, José Lins do Rego, Aurélio Buarque de Holanda, Alberto Passos Guimarães e Valdemar Cavalcanti. Ao admitir que o grupo não estava unido apenas por laços de amizade, mas, também, por interesses comuns - relacionados às suas trajetórias sociais e intelectuais -, o depoimento permite caracterizá-lo como um agrupamento cultural ${ }^{3}$, já que

a roda funcionava no domínio privado de algum membro, em cafés ou em outros espaços públicos, e esparramava uma sociabilidade
Livraria Schimdt Editora, por exemplo ficou conhecida por reunir o Círculo Católico. A Livraria José Olympio Editora por sua vez, reuniu grande número de escritores (Hallewell, 2012: 467; 497). Foi nela, inclusive, que a roda de Maceió se reuniu após alguns de seus integrantes - José Lins do Rego, Graciliano Ramos, Rachel de Queiroz e Santa Rosa migrarem para o Rio de Janeiro (Sorá, 2010).

3. Segundo Raymond Williams (2011: 207-208), os valores e hábitos compartilhados são relevantes para a formação interna do grupo e, além disso, fornecem o elemento de distinção - efeito externo que os fazem se ver como distintos e que poderia fazer com que os outros os enxergassem como um grupo. 
sem etiqueta, entre iguais. Nas rodas, os indivíduos sintetizavam formas de identificação estéticas e políticas como grupo, base de distinção de outras rodas locais, regionais e, inclusive, de outros países (Sorá, 2010: 96).

Aspecto importante é a intensidade dos relacionamentos entre os membros do grupo. Num trecho extraído de carta remetida à Heloísa de Medeiros Ramos, de 22 de março de 1935, Graciliano trata da composição de seu terceiro romance Angústia - e, nela, observa-se o vigor de seu convívio social e intelectual com os escritores José Auto e Rachel de Queiroz:

Em seguida retomarei o trabalho interrompido há cinco meses. Julgo que continuarei o Angústia, que a Rachel acha excelente, aquela bandida. Chegou a convencer-me de que eu devia continuar a história abandonada. Escrevi ontem duas folhas, tenho prontas 95. Vamos ver se é possível concluir agora esta porcaria. [...] Vou dormir. E, às seis horas, quando acordar, conversarei com a Marina e com Luís da Silva, excelentes criaturas, na opinião da Rachel e de Zéauto (Ramos, 2011: 187-188).

Em outra passagem retirada de nova correspondência enviada à esposa, de 24 de março de 1935, outros integrantes da roda de Maceió aparecem. Graciliano, mais uma vez, refere-se ao trabalho de composição de seu novo livro e ao convívio e trocas literárias com os companheiros:

No Relógio Oficial encontrei Zélins, que foi comigo à Nordeste liquidar o negócio das cauções. Daí fomos ao palácio, abraçar o Osman e dizer nossos endereços. Ao descermos, o autor de Banguê quis por força levar-me à casa dele: capítulo do romance novo e almoço. A Naná muito amável. Estou convencido de que ela é uma excelente moça. Em seguida rodamos para casa do Zéauto, onde ouvimos as últimas páginas do livro da Rachel. Zélins deu o fora e eu fiquei, na amolação, conversando literatura e esquecido da política. Rachel falou várias vezes em v. Sempre encantada com as meninas, especialmente com a Clarita, por causa da lembrança que ela tem da Clotildinha. De vez em quando dizia-me uns desaforos por não me resolver a meter a cara no Angústia, que ela acha melhor que os outros dois. Falta de entusiasmo. Sapequei uma folha ontem à noite, mas frio, bocejando (Ramos, 2011: 190).

Com todos esses elementos que os caracterizavam distintivamente lançaram-se em várias frentes da atividade intelectual, ou mesmo incrementaram suas investidas, num momento particularmente importante, do ponto de vista da criação artística, para Alagoas. Esse estado de coisas torna-se mais claro quando se atenta para o fato de que 
José Lins do Rêgo e Graciliano Ramos escreviam romances, Valdemar Cavalcanti fazia crítica literária, Mário Marroquim trabalhava em pesquisas linguísticas, Carlos Paurílio redigia contos poéticos e Aloísio Branco publicava os seus inesquecíveis poemas. Raul Lima, Diégues Júnior, José Auto, Aurélio Buarque de Holanda, Alberto Passos Guimarães, Paulo Malta, Carlos Duarte e Arnon de Mello, em Maceió, no Recife ou no Rio de Janeiro, cometiam também os seus poemas, escreviam os seus contos ou crônicas e começavam a encaminhar-se pelos mais diversos roteiros da vida prática. [...] Rachel de Queiroz levou ali uma parte daqueles quatro anos decorridos entre a conclusão de João Miguel (dezembro de 1931) e a elaboração do Caminho de pedras (outubro de 1936) (Rocha, 2014: 77).

A roda de Maceió constituiu-se como uma rede de sociabilidade e solidariedade, e foi decisiva para a carreira de Graciliano Ramos pelo tipo de ação empreendida por seus integrantes no sentido de se promoverem mutuamente (Sorá, 2010; Silva, 2004).

Não é possível precisar quando Valdemar Cavalcanti - já conhecido na crítica, inclusive carioca, pois contribuía com o prestigiado Boletim de Ariel - passou a atuar como intermediador entre Graciliano e os editores de São Paulo e Rio de Janeiro. Todavia, algumas correspondências tratam das negociações, atestando, assim, o funcionamento da rede de solidariedade mobilizada pelos integrantes do grupo, que será paulatinamente fortalecida à medida que vão se projetando e conquistando espaço na capital do país.

Em artigo publicado no Boletim de Ariel sobre Santa Rosa ${ }^{5}$, Valdemar Cavalcanti trata da maneira encontrada pelo jovem artista e amigo de roda intelectual para dar vazão à sua poesia, expressada nas artes plásticas. Para além desse aspecto, há sinais da convivência deles em Maceió e, ainda, elementos que remetem a certas exigências do campo, notadamente a necessidade de migrar para o Rio de Janeiro, conforme discutido anteriormente.

Nos seus desenhos e nas suas pinturas, Santa Rosa encontrou em verdade uma solução plástica para a sua poesia. [...] Numa época em que ainda se acreditava na existência e no problemático talento de um Corrêa Dias e de um J. Carlos, Santa Rosa ancorou no Rio e venceu, pôs em ordem do dia a sua personalidade inquieta e tão cheia de apetite da ação. [...] Tudo, nesse jovem paraibano, representa uma reação lírica sobre a sua "atmosfera": as suas telas, os seus calungas, os seus raros versos, suas cartas de amigo, sua própria vida. Para viver como Santa Rosa, com o seu humor
4. Valdemar

Cavalcanti nasceu na capital alagoana em 1912. Desde cedo interessou-se pelo jornalismo e pela literatura, publicando, ainda jovem, contos e poemas. Aos 15 anos já era redator de O Semeador e, anos depois, passou a exercer a mesma função no Jornal de Alagoas. Participou de várias atividades culturais em Alagoas, como a fundação do Grêmio Literário Guimarães Passos, da revista Novidade, além de organizar, junto com outros jovens intelectuais, a Festa da Arte Nova - reação ao academicismo e voltada aos assuntos brasileiros e à tradição. Aos 20 anos tornou-se chefe de gabinete do prefeito de Maceió, de quem era sobrinho. Foi jornalista, tradutor, crítico literário, cronista e poeta. Ao longo da vida ocupou diversos cargos em jornais de Maceió, Pernambuco e Rio de Janeiro.

5. Tomás Santa Rosa Júnior nasceu na capital da Paraíba em 1909. Ainda pequeno seu pai, modista, abandonou a família, composta por seis filhos. Sua iniciação artística começou aos nove anos em instituições vinculadas à Igreja Católica. Com 14, além de trabalhar num escritório de contabilidade do governo, concluiu 
o curso secundário no Liceu Paraibano. Aos 19 anos assumiu a direção da Contabilidade da Repartição Pública do Saneamento da Paraíba. Aprovado num concurso para contador do Banco do Brasil, foi para Salvador, depois Recife e Maceió, onde se juntou aos intelectuais do lugar. Expôs suas telas na Noite de Arte Moderna, organizada por Valdemar Cavalcanti, Alberto Passos Guimarães e Moacir Pereira. Pouco depois foi para o Rio de Janeiro com o objetivo de obter maior retorno com sua atividade artística. permanente em presença de um mundo tão velho, com o seu impertinente sans façon, viver tão au dessus de la vie, evadindo-se um dia do Norte para lutar sozinho na cidade grande, abandonando uma vez de repente um emprego do Banco do Brasil, tão displicente nisso tudo, é preciso realmente possuir sobre o reino da razão um quase absoluto domínio da sensibilidade; é preciso chegar-se a um candido e meio infantil senso da realidade, que é o prisma do mundo aos olhos do poeta. Ainda tenho comigo alguns números especiais de exercícios poéticos em versos deixados em Maceió por Santa Rosa, no tempo em que o Banco do Brasil impunha ao grande lírico a disciplina de oito horas diárias de luta contra os números, um livro de ponto a assinar e uma constante e monótona convivência com homens de negócios. Os seus poemas eram uma evasão ao trágico conflito travado cotidianamente e soturnamente entre a sua sensibilidade extremamente sentimental e a unanime incompreensão do ambiente (Cavalcanti, Valdemar. "Santa Rosa Júnior". Boletim de Ariel. Mensario Critico-Bibliographico, Ano III, n. 1, p. 8, Out. 1933).

Ainda que Valdemar Cavalcanti enalteça a perseverança de Santa Rosa ao afirmar que ele teve êxito no Rio de Janeiro sem contar com a ajuda de ninguém, e que assim foi porque sua sensibilidade o distinguia, a biografia do artista plástico mostra um matiz diferente acerca disso. No decorrer da década de 1930, Santa Rosa se notabilizou com seu trabalho de capista, produzindo principalmente para a Livraria José Olympio Editora a partir de 1934 e, depois, como cenógrafo. Antes disso, porém, quando Graciliano Ramos ainda buscava um editor para seu primeiro romance, Caetés, um trabalho de Santa Rosa foi oferecido juntamente do livro à Companhia Editora Nacional. Sem contar ainda com o prestígio que obteria depois, em razão de seu trabalho, Santa Rosa dependia da mediação de seus companheiros em melhores condições, do ponto de vista do reconhecimento, para se afirmar como produtor cultural.
Maceió, 19 de abril de 1933.

Companhia Editora Nacional

São Paulo

Prezados amigos:

enviando com a presente o recorte do meu último rodapé de crítica literária, aproveito a oportunidade para tratar de assunto que muito diretamente afeta os interesses da indústria do livro, de que esta Editora se tem feito a casa de maior relevo em cifras de produção e seleção. Quero consultar se interessa aos amigos a edição de um admirável livro nordestino, de autoria do roman- 
cista Graciliano Ramos. O CAETÉS é um romance que focaliza, com uma extraordinária força de descritivo humano, uma época de vida de província, com o seu cotidiano tranquilo, com as suas almas pacatas, mas com os seus dramas anônimos e dolorosos. É um volume que revela ao Brasil, na opinião de um grande crítico que é Prudente de Morais neto, em carta particular, uma das suas mais seguras organizações de romancista. Um livro grande, não por nos mostrar postais da paisagem física de uma cidadezinha do interior, mas por nos exibir em água-forte o panorama humano de algumas vidas em desordem dentro da rotina do dia-a-dia sertanejo. É curioso o seguinte: tendo-se interessado por lançar o romancista nordestino à publicidade, o editor A. F. Schimdt obteve em primeira mão os originais do livro. Com a Revolução e outras coisas piores o CAETÉS encalhou. Mas Schmidt deu-o a ler a alguns dos de sua grande roda. E criou-se no pequeno círculo uma sensação de surpresa: a de uma boa descoberta. Uns até levaram seus comentários à imprensa. Lembro-me bem de um artigo de Jorge Amado, o romancista de O PAIZ DO CARNAVAL, no número de novembro do BOLETIM DE ARIEL, no qual se encontra o nome de G. Ramos na vanguarda dos maiores escritores do Norte. E ainda hoje estão empatadas, em composição, as 220 páginas do livro, - na Sociedade Impressora Paulista - o que aliás poderá facilitar, a esta Editora, caso queira entrar em negociações com a edição, um largo beneficiamento econômico. Com a saída do CAETÉS, poderá entrar para a fecundação dos prelos, um outro romance de Graciliano Ramos, o mais recente: S. BERNARDO - retrato da vida rural sertaneja.

Desejo saber se a esta Editora, sempre tão atenta em lançar ao nosso público os grandes livros brasileiros, interessa a edição do romance do meu amigo. E se assim for, que condições poderá [pro]por a Graciliano Ramos. A composição da tipografia da rua Sc[parte fragmentada]ro barateará em muito a publicação, e para a capa já possui [parte fragmentada]tor um desenho admirável e expressivo de Santa Rosa Junior.

No sentido de fornecer aos ilustres amigos uma ráp[ida e] fragmentária visão do valor do romance e do romancista [parte fragmentada] envio junto a cópia das duas últimas páginas do CAETÉS.

Aguarda resposta dentro da possível brevidade, [parte fragmentada] confrade

Valdemar Cavalcanti

33, Barão de atalaia

Maceió - Alagoas (Arquivo IEB-USP, Fundo Graciliano Ramos, Coleção Correspondência de Terceiros, código do documento GR-CT-003). 
Santa Rosa contava, portanto, com uma rede de solidariedade que fora construída no período em que viveu em Maceió. Já inserido no grupo, Graciliano também se valeu dessas prerrogativas. Os meios utilizados por Valdemar Cavalcanti para promover o amigo e companheiro de roda foram vários. Logo de início utiliza-se de sua condição de crítico para conferir a Caetés credibilidade, atribuindo-Ihe vários qualificativos.

A fim de corroborar o valor do romance, menciona a opinião de outro crítico, Prudente de Moraes Neto, para quem o livro de Graciliano o distinguia como grande romancista. Deve-se observar que a impressão desse crítico chegou a ele por meio de carta particular. Tratava-se de um amigo, mas também crítico literário, alguém autorizado a emitir juízos, e neto do ex-presidente Prudente de Moraes, condição que fornecia um tipo de prestígio diferente, exterior à literatura. Graciliano agora contava com o auxílio do crítico e companheiro de roda já reconhecido e, também, de alguém externo ao grupo, Prudente de Moraes Neto, que conferia maior credibilidade a Valdemar Cavalcanti - que negociava o livro com a Companhia Editora Nacional -, bem como ao escritor que procurava alguém disposto a publicá-lo. Na tentativa de convencer a editora, o crítico alagoano remete-se também a Jorge Amado, que pouco antes havia sido lançado pela editora de Augusto Frederico Schmidt, que, aliás, foi o responsável por lançar vários escritores da segunda geração modernista.

Esse tipo de recurso foi bastante utilizado pelos grupos, e particularmente pela roda de intelectuais de Maceió.

As trajetórias dos participantes do grupo de Maceió indicam que essa roda imbricava com as de outras capitais da Região Norte, e seus membros já contavam com algum grau de reconhecimento entre os pares, e somente entre estes, dos outros círculos de produção restrita (Sorá, 2010: 103).

Esse expediente funcionava como uma anuência. Alguém já inserido no centro da produção literária, e obviamente reconhecido pelos pares, fazia a mediação com o propósito de facilitar a entrada de um autor oriundo das regiões periféricas. Não se trata, aqui, de afirmar que apenas isso garantiria aos escritores tanto a entrada quanto a permanência nesses círculos mais restritos de escritores. Fatores literários, propriamente, eram também determinantes. Ao enfatizar aquele recurso procuro mostrar que não bastava ter um bom livro, era necessário cumprir uma série de requisitos sem os quais certamente os planos dos pretendentes à carreira literária seriam atrapalhados. 
A trajetória de Graciliano, desde sua primeira investida ainda na década de 1910, mostra isso. Naquele momento ele ainda não contava com o apoio de figuras bem colocadas e, invariavelmente, teve seus planos frustrados. No início do decênio de 1930, mais bem posicionado, já que o cabedal de relações sociais que construiu contava com atores que possuíam algum reconhecimento e trânsito pelo centro cultural, ou, em outros termos, detentor de um lastro institucional robusto, representado pela roda de intelectuais de Maceió, que não apenas o reconhecia socialmente como escritor, mas o auxiliava em suas investidas, conseguiu entrar mais bem armado nas disputas.

Isso pode ser apreendido de duas maneiras. Uma delas diz respeito à forma como os companheiros de roda de Graciliano o apresentaram, ou seja, ao tipo de recepção que fizeram dos seus primeiros romances. A outra remete-se à trajetória editorial do escritor alagoano, aos recursos utilizados por seus companheiros para levá-lo a uma editora prestigiada, que lhe garantisse inclusive recompensas simbólicas. Ambas as coisas evidenciam a importância dessa rede bem estruturada de alianças que não se limitava ao grupo do qual fazia parte, mas que requeria apoio externo de agentes legitimados.

Quando a atenção se volta para as negociações, percebe-se a importância de se contar com bases institucionais sólidas como as que os grupos intelectuais forneciam, pois o auxílio prestado por Valdemar Cavalcanti aumentou o poder de barganha de Graciliano. Como foi visto, seu livro não apenas foi oferecido a outra editora, como também recebeu a chancela de mais um crítico, fator que o ajudava, ainda mais se for levado em consideração que o crítico em questão, Prudente de Moraes Neto, distinguia-se também por seu prestígio social, já que era neto de um ex-presidente da República, e com trânsito entre a intelectualidade.

Nem mesmo Schmidt, que era também crítico literário, prescindiu de um julgamento que poderia dar maior visibilidade a Caetés. Conforme correspondência enviada por Rômulo a Graciliano, já citada, vê-se que além do próprio parecer - implícito, já que estava disposto a publicá-lo -, o editor havia submetido o livro a dois dos principais críticos da época, Tristão de Athayde e Agripino Grieco. Certamente Schmidt se valeria disso como estratégia comercial para impulsionar as vendas. Já aqui é possível notar que embora a finalidade fosse a mesma - publicar o livro -, esse tipo de apoio era diverso daquele levado adiante pelo grupo. O tipo de sociabilidade que a convivência no grupo encerrava - espraiando-se na amizade e nas trocas literária - e, sobretudo, o lastro consistente que ele criava, além de dar suporte aos seus integrantes, gerava entre eles um tipo bastante particular de solidariedade ${ }^{6}$.
6. Gustavo Sorá

(2010) e Simone Silva (2004) argumentam que havia um compromisso recíproco entre os membros da roda de Maceió, isto é, um favor teria de ser compensado por outro, gerando, assim, um sistema de dons e contradons que os favoreceria na medida em que isso se refletia em indicações e proteção. 
7. Apenas Rachel de Queiroz não dependeu da roda de Maceió para a edição de seu primeiro romance, O quinze. Quando o livro foi publicado, em 1930, ela ainda residia no Ceará com sua família, e foi o pai quem custeou a primeira edição junto à Gráfica Urânia, de Fortaleza.

\section{Não se deve} perder de vista que Graciliano Ramos fora reconhecido como escritor em 1910, quando foi procurado pelo Jornal de Alagoas para responder a um inquérito literário. Esse tipo de reconhecimento, ainda que importante, limitava-se a um espaço bastante restrito-Alagoas, ou, na melhor das hipóteses, à Região Nordeste -, já que isso não Ihe proporcionou qualquer vantagem quando foi para o Rio de Janeiro, em meados do decênio de 1910, na tentativa de levar adiante seu plano de trabalhar em atividades intelectuais, por exemplo, no jornalismo e na literatura.

9. Essa peculiaridade do grupo de Maceió foi mencionada por Antonio Candido em artigo sobre Caetés. Nas palavras de Candido: "Quando Caetés foi publicado, havia em Maceió um grupo intelectual que funcionou como
Graciliano Ramos passou a frequentar a roda de Maceió quando já estava próximo dos 40 anos, após ter vivenciado uma frustração na literatura - já que não conseguira se firmar em sua primeira passagem pelo Rio de Janeiro -, trabalhado como comerciante e ocupado cargos na administração pública de Alagoas. Para se ter uma ideia, Valdemar Cavalcanti era quase 20 anos mais jovem, assim como Tomás Santa Rosa, Rachel de Queiroz e Aurélio Buarque de Holanda. José Lins do Rego tinha por volta dos 30 anos. Apesar da idade e da experiência acumulada na literatura, Graciliano chegava ao grupo em condições similares à dos demais, todos mais jovens que ele, pois ainda tentava publicar algo de fôlego.

Nesse sentido, o aspirante a romancista valeu-se bastante de todo arcabouço institucional conferido pelo grupo. Nada fortuito é o fato de ganhar o reconhecimento social de escritor por parte de seus integrantes ${ }^{8}$, que eram ainda jovens e colocavam-se como representantes de uma nova geração. Foi colaborador da revista Novidade - fundada por Alberto Passos Guimarães e Valdemar Cavalcanti -, que se tornou um meio de expressão importante para os intelectuais de Alagoas (Lebensztayn, 2010). Graciliano teve em seus novos companheiros leitores primeiros de suas produções literárias e, principalmente, contou com o apoio deles para se projetar no mundo das letras ${ }^{9}$, o que tentara, até aquele momento, sem dispor de uma base de apoio sólida.

A função dos componentes do grupo como mediadores entre regiões periféricas e centrais, do ponto de vista da produção e consagração literárias, pode ser apreendida ao se analisar as correspondências trocadas com editores, bem como pelos artigos que anunciavam e davam as primeiras impressões sobre os livros que produziam. Tudo isso numa estratégia de promoção, imprescindível para se colocarem nos espaços centrais do campo.

Daí ser necessário acompanhar, ainda, o processo de negociação para a edição dos primeiros romances de Graciliano durante a década de 1930. Por um lado, isso deixará claro o funcionamento efetivo do grupo - as estratégias mobilizadas para a consecução de seus objetivos, ou seja, a promoção de seus integrantes -, por outro, e ainda que seja também parte das estratégias de grupo, como conseguiram compor o catálogo da editora mais prestigiada do Brasil concernente à edição de literatura brasileira, a Livraria José Olympio Editora.

Nesse ínterim, como se entrevê pela autoria do artigo sobre Santa Rosa, publicado no Boletim de Ariel, e na correspondência enviada à Companhia Editora Nacional na tentativa de publicar o livro de estreia de Graciliano Ramos, Valdemar Cavalcanti teve papel fundamental, figurando mesmo como importante articulador e divul- 
gador do grupo. Há outras evidências de que ele cumpria esse papel, possibilitado pelo relativo destaque que alcançou devido ao seu trabalho como crítico e colaborador de uma importante revista do Rio de Janeiro. Em carta remetida ao crítico alagoano por Sebastião de Oliveira Hersen, proprietário da Adersen Editores, depreendem-se aspectos da função de intermediador que aquele desempenhava entre os autores - companheiros de roda intelectual e amigos - e o editor.

Rio, $13 / 04 / 33$

Meu caro V. Cavalcanti:-

Hoje é dia 13, véspera do último dia a que tenho direito de editar o "Caetés". Não sei se V. será capaz de avaliar o aborrecimento de que estou possuído pela minha impotência financeira atual.

Devo-Ihe uma explicação detalhada:

A ADERSEN-EDITORES era composta até Fevereiro do corrente ano de 2 sócios: Adolfo Aizen [AD...] e Sebastião de Oliveira Hersen [... ERSEN]. Acontece que o Adolfo, muito versátil, é o termo, desistiu de prosseguir na empresa, alegando falta absoluta de tempo para se dedicar ao assunto, e outras coisas. A verdade nua e crua é que não teve coragem suficiente para enfrentar as primeiras e inevitáveis dificuldades, para as quais uma série enorme de fatores concorriam, notadamente a depressão geral do comércio do país. Esperava que as compensações fossem largas e imediatas, o que é uma grande ilusão. De outra tempera, afeito a qualquer espécie de luta, assumi inteira responsabilidade do ativo e passivo da firma, desfalcando-a, porém, do capital do amigo, que continuou a ser. A ADERSEN-EDITORES (conservo o nome) não sofreu nem sofrerá solução de continuidade, mas ficou abalada, pois não sendo rico estou ainda lutando com dificuldades muito sérias para cobrir o desfalque.

Daí nasceu a impossibilidade de imprimir imediatamente o "Caetés", extinguindo-se amanhã o prazo (aliás curto), que eu próprio solicitei, pois todo o dinheiro de que dispunha na ocasião empreguei na edição da "Bagaceira", que vai me dar resultados apreciáveis, mas só depois de 3 meses.

$\mathrm{Na}$ expectativa de conseguir, ainda, meu intento, comuniquei-me com os impressores paulistas que estavam fazendo o livro para o Schmidt, na esperança de comprar, por preço razoável, a edição, que me disseram estar pronto há muito tempo, lá. O Gerente da firma esteve aqui no Rio, comigo, mostrou-me as provas (222 páginas), já revistas pelo Graciliano Ramos, mas o orçamento que me fez foi um orçamento comum, sem considerar o chumbo empatado há quase 2 anos, tempo gasto, iminência de perder tudo isso, desde que eu mandasse fazer o livro noutra tipografia etc. etc. Diante do fato, não chegamos a acordo e o "Caetés", malgré tout, público restrito de alta qualidade, cujo papel foi não apenas receber o livro, mas manifestar o seu juízo sobre ele" (Candido, 2012: 127). 
continuou na mesma. Tudo isso, eu sei que não interessa ao Graciliano Ramos, que já perdeu um tempo enorme com o Schmidt e não está disposto a perder outro tanto comigo. Mas faço questão de chamar sua atenção para a face humana do caso.

Até o princípio de Maio próximo farei rápida viagem ao Norte, onde vou buscar dinheiro para intensificar a produção de minha editora e, portanto, consolidar sua vida. Estarei aí em Maceió, portanto, muito breve, quando poderemos, se lhes interessar ainda, combinar outro prazo para a saída do "Caetés", assim como para o "S. Bernardo". Mas só Ihe proporei qualquer modalidade de negócio quando estiver com o dinheiro no bolso, isento, pois, de nova gafe. Converse com o Graciliano Ramos e me diga depois qualquer coisa. Aliás, o Gerente da Impressora Paulista me disse que já recebera proposta de outra editora com referência ao "Caetés". Os originais dele e do "S. Bernardo" estão em meu poder, à inteira disposição do autor, não pagando aluguel pelo tempo em que continuarem aqui, assim como o desenho do Santa Rosa que, no caso do "Caetés" ser feito noutra parte, eu faria questão fechada de oferecer, gratuitamente, é claro.

Aguarde minha breve chegada a Maceió e então conversaremos melhor e nos conheceremos pessoalmente, já que V. não quis vir aqui em Fevereiro, como me falou uma vez em carta. Dê um abraço no Zélins, a quem escrevi ontem.

Do amigo certo, S. O. Hersen (Arquivo IEB-USP, Fundo Graciliano Ramos, Coleção Correspondência de Terceiros, código do documento GR-CT-002).

Fica evidente, assim, a participação de Valdemar Cavalcanti na intermediação das conversas entre Graciliano Ramos e Sebastião de Oliveira Hersen, que, com a saída de seu sócio, Adolfo Aizen, tornou-se o único proprietário da Adersen Editores. Aproximadamente três anos após iniciar as negociações com Augusto Frederico Schmidt, o escritor ainda procurava um editor para Caetés. E Hersen utilizou-se da mesma justificativa dada por Schmidt para não editar o livro dentro do prazo acordado, alegou estar enfrentando dificuldades financeiras.

A diferença agora é que Graciliano, já integrado ao grupo de intelectuais da capital alagoana, contava com um cabedal de relações sociais que o auxiliava em suas investidas literárias, exemplificada, nesse caso, pela mediação exercida por Valdemar Cavalcanti, que provavelmente tentava fazer de sua preeminência e das relações que já havia costurado com críticos e escritores reconhecidos um trunfo para beneficiar os membros do grupo, particularmente Graciliano Ramos, como foi possível apreender tanto pela carta que recebeu de Hersen como pela corres- 
pondência que enviou à Companhia Editora Nacional, a quem, conforme foi visto, ofereceu não apenas os livros do escritor alagoano, mas também a ilustração de Santa Rosa.

A despeito das tentativas do crítico alagoano para conseguir um editor para os livros de Graciliano Ramos, Caetés acabou saindo pela Livraria Schmidt Editora no final de 1933 e S. Bernardo pela Editora Ariel quase um ano depois. Aliás, essas editoras, bem como a Adersen Editores foram as responsáveis por lançar vários escritores que estrearam no início dos anos 1930. Como foi visto por meio da correspondência enviada por Sebastião de Oliveira Hersen a Valdemar Cavalcanti, o segundo romance de Graciliano também fazia parte das negociações. Inclusive, S. Bernardo foi oferecido, juntamente de Caetés, à Companhia Editora Nacional, conforme carta remetida à essa editora, mais uma vez, pelo crítico. Além disso, $S$. Bernardo acabou sendo datilografado por ele (Moraes, 2012: 97) e lido, antes de ser editado, pelos companheiros de roda, que atuaram incisivamente na promoção de Graciliano.

Antes de continuar tratando disso, deve-se atentar para um dado interessante quando se estuda o incipiente campo literário brasileiro da primeira metade do século XX. Assim como Caetés, que fora editado por Augusto Frederico Schmidt - que, entre outras atividades, ocupava-se da crítica literária, sendo até mesmo reconhecido -, S. Bernardo foi editado por outra editora que tinha como proprietários críticos renomados, Gastão Cruls e Agripino Grieco. Essa circunstância beneficiou Graciliano na medida em que teve boa acolhida por críticos prestigiados, sediados no Rio de Janeiro, local onde se formavam as opiniões que concorriam mais fortemente não apenas para a inserção daqueles que estavam se lançando nas atividades intelectuais, como era o caso do escritor alagoano entre os anos de 1933 e 1934, mas também para a permanência deles em posições vantajosas no campo literário.

Mas a mediação dos seus companheiros não se limitava a conseguir um editor. Com o lançamento de Caetés e, depois, S. Bernardo, as estratégias se voltaram para que os livros ficassem em evidência. E não havia recurso melhor para fazerem isso do que se valer da condição de críticos, como eram alguns membros da roda, e principalmente de colaborarem com uma das mais importantes revistas da época, o Boletim de Ariel.

Nessa direção, o crítico Valdemar Cavalcanti tratou de recepcionar Caetés, analisando-o por meio de um curto artigo publicado na referida revista. Segundo ele, 
10. Na página 81 , do mesmo número, foi reproduzido um capítulo do livro e, ao final, alude-se ao fato de estar por ser lançado. Esse recurso foi fartamente utilizado como maneira de chamar a atenção dos leitores para as obras que estavam por ser publicadas.

\section{Miceli (2001)}

evidencia que

um processo de substituição de importações - devido aos efeitos da crise econômica do final dos anos $1920-$, o desenvolvimento do mercado editorial no eixo São Paulo-Rio de Janeiro, no decorrer da década de 1930, e a elevação do romance como gênero rentável concorreu para a profissionalização de um pequeno número de escritores profissionais.

Paralelamente, a ingerência estatal nos assuntos culturais, sobretudo no sentido de fomentar uma cultura nacional cooptando mesmo intelectuais de diferentes matizes ideológicas para levar adiante tal projeto acabou favorecendo os autores cujas produções flertavam com a temática da realidade brasileira. Foi nesse contexto que os escritores do Nordeste, e particularmente da roda de Maceió, despontaram no cenário nacional.
O que nos impressiona no romance de Graciliano Ramos é a sua força de humanidade, é a sua plástica expressão de vida e movimento. A realidade, atingida pelos processos diretos e incisivos do escritor alagoano, chega a uma rara condensação. [...] Sente-se no Caetés a força intima do documento humano; ele é uma luminosa fotografia da multidão, realizada por um que acredita naquela realidade histórica dos acontecimentos, tão dentro dos grandes romances, de que Duhamel falou num recente ensaio.

Talvez o que mais influa para dar ao Caetés toda essa impressão de vida, toda essa comunicabilidade, seja a segurança de sua fatura, o admirável de sua realização. Graciliano Ramos tem, como romancista, qualidades de poucos no Brasil. Tem uma simplicidade, uma disciplina, uma secura de fala que fazem o caráter meio exótico de sua fisionomia. [...]

Em muitas de suas páginas a gente percebe que Eça deixou nele marcas fundas; muitas de suas qualidades e alguns de seus defeitos se fixaram, sem o querer do autor, no seu caráter. Porém, no corpo do romance há uma expressão pessoal do narrador. E esse poder de animar os homens e os fatos, em Graciliano Ramos, não é resto de banquete de Eça de Queiroz: é cozinha especial, é comida de primeira mesa.

Quando eu li Caetés, há três anos, senti uma impressão de caricatura: caricatura de massa, com a grandeza natural da boa caricatura mas também com as desvantagens de seu sentido de deformação da realidade, apenas. Sugestionei-me que Graciliano Ramos se especializara em maus tratos com os seus heróis, dando-lhes uma vida de escravos e não de gente. E nunca uma impressão foi mais falsa, nunca me traí tanto a mim mesmo (Cavalcanti, Valdemar. "O romance 'Caetés'". Boletim de Ariel. Mensario Critico-BibliographiCo, Ano III, n. 3, p. 73, Dez. 1933)10.

O artigo apresenta, do início ao fim, o mesmo tom, e não me parece exagerado dizer que seja laudatório. Por meio da análise dos trechos transcritos, vê-se que o crítico procurou mostrar os pontos fortes do romance. Ao se valer de certas expressões que procuravam causar um efeito positivo, vai reforçando o que, para ele, caracterizaria e engrandeceria Caetés, isto é, sua capacidade de representar a realidade ${ }^{11}$. Aos poucos vai construindo a imagem que pretendia fixar acerca de Graciliano Ramos, que se singularizaria entre os romancistas do país. Ao realizar comparações, coloca o escritor alagoano ao lado do prestigiado Eça de Queiroz. Para Valdemar Cavalcanti, como tudo no romance é grande, até mesmo o que seria um ponto fraco, observado por ele em uma primeira leitura, revela-se como equívoco de julgamento, e assim ressalta, uma vez mais, as qualidades do livro e de seu autor. 
A referência à leitura de Caetés, três anos antes do artigo publicado no Boletim de Ariel, é um indício da amizade e, sobretudo, da sociabilidade literária entre os integrantes da roda de Maceió, empenhados na promoção e no reconhecimento de seus membros nos centros culturais São Paulo e, principalmente, Rio de Janeiro, a partir dos anos 1930, por ser a sede das principais instâncias de consagração, entre elas a editora de José Olympio.

A recepção de Caetés por amigos e companheiros de grupo não se encerrou no artigo de Valdemar Cavalcanti. Num texto mais extenso, em outro número do Boletim de Ariel, Aurélio Buarque de Holanda o analisou.

Relendo agora o Caetés, avivou-se a boa impressão que ele me deixara há três anos passados, quando o li no original. Trata-se realmente de um livro sério. [...] Escreve quase como quem passa telegrama, pagando caro por cada palavra. [...]

O sr. Graciliano Ramos é um admirável técnico do romance. Nenhum dos nossos romancistas vivos o iguala neste ponto. Seu livro é admiravelmente bem construído, um livro em que nada se perde e a que nada falta. Tudo nele é muito justo, muito medido, muito calculado. Daí lhe virá, também, a frieza apontada, e mesmo uma certa monotonia. $O$ tédio do perfeito. Camillo encontrou no Crime do Padre Amaro "admiráveis defeitos". É de tais admiráveis defeitos que o Caetés necessitava para ser um grande romance. Rigorosamente ele é um bom romance. Poderia até chamá-lo de formidável se o comparasse com muito romancezinho ordinário que vem aparecendo de há uns tempos para cá com a fama de grande. Mas convém fazer uma reação contra essa crítica obtusa ou safada que desmoraliza cada vez mais os adjetivos. Os tais grandes romances são em geral medíocres ou pouco mais que medíocres; Caetés é bom, como Menino de Engenho, Os Corumbas e poucos outros dos ultimamente aparecidos.

Que admirável fixador de tipos, o autor de Caetés! [...] Dialogador excelente, o sr. Graciliano Ramos abusa, entretanto, do diálogo, fazendo-nos pensar às vezes que estamos a ler uma peça de teatro. $[\ldots]$

Muito crítico verá certamente no sr. Graciliano Ramos um insensível, um homem de coração fechado aos aspectos dolorosos da vida. O seu estilo seco, a sua composição metódica, a ironia cortante, o travo de pessimismo, o amargo humor espalhados no Caetés - tudo isto, que concorre para dar a impressão de absoluta frieza, não impede, no entanto, que haja no livro páginas cheias de viva comoção. [...]

Como Machado de Assis, de quem se aproxima pela secura do estilo, o sr. Graciliano Ramos não é homem de exaltações panteístas. 
[...] Mas, dentro dessa concisão, talvez mesmo em consequência dela, o sr. Ramos é um paisagista seguro. [...]

A construção de certas frases, certos achados de expressão, mesmo certas palavras características do estilo de Eça de Queiroz, traem a influência deste escritor sobre o romancista de Caetés. Quando digo influência, deve-se ver que não acho imitação consciente. $\mathrm{O}$ que há são pontos de contato resultantes de longa infiltração, através de uma leitura apurada e contínua. [...]

Os defeitos apontados em Caetés - insignificantes na sua maioria - não chegam a obscurecer, antes põem em destaque, o que o romance tem de realmente belo. Com ele o sr. Graciliano Ramos pode, sem favor, formar na fileira dos melhores romancistas do Brasil. E dentro de poucos meses - anuncio-o com o maior prazer aos leitores do Boletim - a publicação de São Bernardo, que já conheço, revelará ao país um dos seus grandes, dos seus maiores romancistas de todos os tempos (Holanda, Aurélio Buarque de. "Caetés". Boletim de Ariel. Mensario Critico-Bibliographico, Ano III, n. 5, p. 127-129, Fev. 1934).

Há nesses trechos selecionados duas referências à amizade e sociabilidade literária entre Graciliano e Aurélio. Uma trata da leitura dos originais de Caetés três anos antes dele ser publicado; e outra alude ao segundo romance do escritor, S. Bernardo, que o crítico já conhecia e que era, na opinião dele, melhor do que aquele que o antecedera.

Diferente do que fez Valdemar Cavalcanti, Aurélio Buarque optou por discorrer sobre os erros e acertos do livro de estreia de Graciliano, colocando-o ao lado de outros bons romances publicados na época, inclusive o de seu companheiro de roda José Lins do Rego. Contudo, de maneira semelhante àquele, Aurélio não economizou nas comparações com o propósito de valorizar as técnicas do romancista alagoano, e apesar de tratar também dos pontos fracos, o elogio aparecia frequentemente. Em ambos os casos as análises da obra, propriamente, são superficiais. Finalmente, ao emitir seu juízo sobre o próximo romance de Graciliano Ramos, colocava-o entre os grandes da literatura brasileira. Em outros termos, ao tratar Caetés, pelo menos aparentemente, de maneira imparcial, Aurélio Buarque de Holanda aparecia como alguém desinteressado e capaz de emitir um julgamento justo sobre S. Bernardo.

Ao avaliar o artigo dessa maneira, não quero suscitar dúvidas sobre a integridade do crítico, tampouco sobre a qualidade de Caetés, que outros críticos avaliaram, apontando, assim como Aurélio, seus eventuais erros e acertos. Minha intenção é outra: evidenciar como a maneira de construir o argumento - aparentemente isen- 
to de qualquer interesse -, de fazer referências ao conhecimento anterior da obra e à convivência com seu autor, sugere uma estratégia de promoção do companheiro de roda. E, nesse sentido, o fechamento do texto é esclarecedor, pois enaltece um livro a ser publicado, aguçando o interesse dos leitores. Esse tipo de recepção foi bastante útil no momento em que Graciliano ainda não tinha tanta projeção, já que contava apenas com o reconhecimento em sua região e de alguns grupos no Rio de Janeiro, como o que frequentava a roda de Augusto Frederico Schmidt, bem como de Gastão Cruls e Agripino Grieco, seus primeiros editores, além de Prudente de Moraes Neto.

Apesar de mencionarem S. Bernardo, aqueles críticos, ou qualquer outro companheiro de roda de Graciliano, não escreveram sobre ele no Boletim de Ariel. Cumprida essa etapa que pretendia dar visibilidade ao escritor alagoano para além dos limites regionais, não havia mais a necessidade de semelhante prática. Outros críticos, e entre eles um ou outro aliado de rodas intelectuais próximas, como Aderbal Jurema e Jorge Amado, passaram a recepcionar seus romances no momento em que iam sendo publicados no decorrer da década de 1930. No entanto, não se deve perder de vista que, ao anunciarem o segundo romance de Graciliano Ramos, Valdemar Cavalcanti e Aurélio Buarque de Holanda o enalteceram, tratando-o como superior a Caetés. Dessa maneira, a avaliação dos críticos poderia ser capitalizada para o segundo romance do escritor, até mesmo potencializada. Diante disso, arrisco-me a afirmar que a recepção de S. Bernardo foi feita pelo grupo exatamente no momento em que Caetés era avaliado.

Outra coisa não negligenciável é o fato de o segundo livro de Graciliano ter sido publicado pela Editora Ariel, cujos proprietários eram Gastão Cruls e Agripino Grieco, responsáveis pela revista Boletim de Ariel. Assim, tanto a divulgação do livro como a sua recepção foram entremeadas também pelos interesses dos críticos-editores enquanto empresários. Além da recepção feita pelos companheiros do escritor no momento em que avaliavam seu romance de estreia, S. Bernardo ganhou nas páginas da revista nota sobre sua publicação vindoura, capítulo e duas avaliações ${ }^{12}$.

\section{A consagração literária de Graciliano Ramos}

O terceiro romance de Graciliano, Angústia, teve itinerário diferente. Além do escritor ser relativamente conhecido no Rio de Janeiro, uma vez que seus outros dois romances foram publicados por editores dessa cidade e obtiveram boa recepção por parte da crítica, sua prisão sob a acusação de ser comunista, em 1936, converteu-se em vantagem na medida em que, por um lado, ficou marcado como injustiçado pelo regime autoritário de Getúlio Vargas e, por outro, por ter se aproximado
12. Para mais informações acerca da recepção feita por Aderbal Jurema e Jorge Amado, no Boletim de Ariel, e Agripino Grieco, em O Jornal, consultar Wellington Pascoal de Mendonça (2018) $\mathrm{O}$ artigo de Grieco, igualmente favorável, torna-se relevante por ele ocupar uma posição de destaque entre os críticos do período, assim, seus pareceres tinham o poder de impulsionar ou atravancar a inserção dos novatos, e também porque ele tinha interesse comercial em $S$. Bernardo, pois, conforme mencionei, o crítico era um dos proprietários da Editora Ariel. A recepção de todos eles serve ainda como índice dos relacionamentos e alianças entre rodas de regiões diversas, necessárias para aqueles que vinham de polos de produção secundários. 
13. Com base na leitura dos recortes de jornais encontrados no acervo do escritor no IEB-USP, e nas informações extraídas de biografias, exploro a evidência de que sua imagem como intelectual de esquerda, tendo em vista as imbricações entre os campos político e literário, pode ter influenciado na maneira como foi recepcionado por parte da crítica, dos escritores e do público. Além da prisão de Graciliano, em 1936, e sua filiação ao PCB, em 1945, seus posicionamentos na imprensa reforçam a correlação quase simbiótica entre o escritor e o comunismo, do qual o partido também se valeu devido à projeção que o escritor alcançava. Não se trata, contudo, de dizer que Graciliano atuou deliberadamente nesse sentido, mas dadas as condições do campo literário naquele momento, esses fatores parecem ter atuado. da esquerda - inclusive se filiando ao PCB quando o partido voltou à legalidade, em 1945 -, contou com apoio institucional, nada negligenciável, já que a sigla controlava algumas importantes instituições culturais ${ }^{13}$.

No entanto, ele continuava recebendo o auxílio de seus companheiros de roda na esfera editorial. Se esse papel foi cumprido anteriormente por Valdemar Cavalcanti quando negociava seu primeiro livro, a ida de José Lins do Rego para o Rio de Janeiro foi particularmente importante porque lá se aproximou de José Olympio, que se tornaria o principal e mais prestigiado editor de literatura brasileira, participando ativamente da transferência de Rachel de Queiroz e Graciliano Ramos para a editora dele. Para todos eles essa mudança representou um passo adiante nas suas carreiras. Claro que essa inflexão não ocorreu de maneira imediata, e dependeu da legitimação da Livraria José Olympio Editora como a casa do romance brasileiro e, também, do tipo de relação que tiveram com José Olympio.

O momento de virada na história da editora iniciou-se com sua transferência de São Paulo para o Rio de Janeiro, em 1934. Ao considerar apenas os episódios que se relacionam aos autores da roda de Maceió, pouco tempo depois de José Lins do Rego passar a ser editado por José Olympio foi criada a coleção "Ciclo da cana-de-açúcar", que tinha como proposta conferir unidade aos livros do escritor. Foi nesse momento que ele estreitou relações com o editor, atuando como uma espécie de agenciador entre a Livraria José Olympio Editora e os seus companheiros de grupo (Sorá, 2010).

Foi sob esse pano de fundo, como se depreende dessa breve retrospectiva, que Graciliano negociou seu terceiro romance com o editor José Olympio. E, assim como ocorrera das outras vezes, foi um companheiro de roda que intermediou o negócio. O escritor trata disso na correspondência enviada à sua esposa em 1935, quando ainda trabalhava na administração pública de Alagoas.

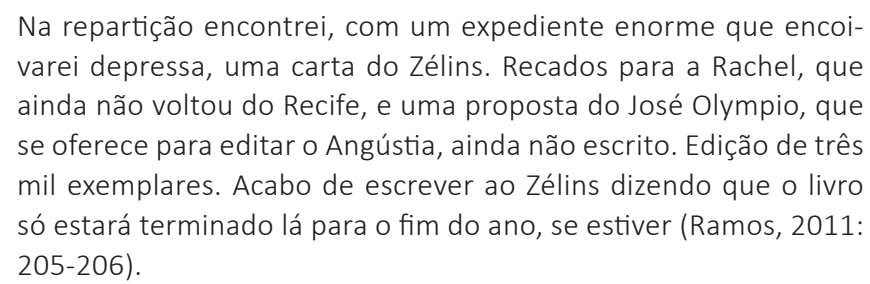

Enquanto transitava de prisão em prisão, seu livro finalmente foi editado pela Livraria José Olympio Editora. No Boletim de Ariel saíram artigos avaliando Angústia, mas, dessa vez, o livro não foi recepcionado por alguém que pertencia ao grupo, 
nem que fizesse parte da rede de solidariedade mais próxima do escritor. Isso pode ser observado também em relação a Vidas Secas. Recepcionaram os livros, respectivamente, Lydia de Alencastro Graça e Lúcia Miguel Pereira. Isso, para mim, é indício de que Graciliano havia sido aceito e legitimado entre os críticos, assim, não necessitava mais dos expedientes de que lançaram mão seus companheiros de roda no sentido de o recepcionar e torná-lo visível perante a crítica carioca ${ }^{14}$.

Daí por diante, tratava-se de um escritor reconhecido pelos pares e prestigiado pela crítica. Acredito, assim, que não seja nenhum exagero supor que a relação dele com a Livraria José Olympio Editora ter sido baralhada. Se antes o prestígio da editora, bem como a possibilidade de auferir retornos financeiros maiores, teria o motivado a negociar com ela seu romance Angústia, agora, prestes a ser definitivamente consagrado, o que ocorreria com a publicação de Vidas Secas, cerca de dois anos depois, e ainda que não tivesse consciência, foi capaz de transferir à editora parte do reconhecimento simbólico que conquistara, já que ambos ocupavam, desse ponto de vista, posições homólogas no campo literário brasileiro.

Uma análise apressada poderia sugerir que o escritor alagoano teve uma ascensão extraordinária, pois pouco tempo depois de publicar seu primeiro romance obteve a consagração. Não obstante, várias foram as constrições que teve de superar. Na esfera pessoal, as finanças volta e meia o deixavam numa situação difícil, e várias vezes teve de morar longe da esposa e dos filhos, quando não morar com um ou outro filho para amenizar a escassez material, remediada pelos trabalhos de tradutor que realizava na Livraria José Olympio Editora e pelos textos que escrevia sob encomenda. Outro fator que merece atenção era a sua idade relativamente avançada quando comparada à idade com que estrearam seus outros companheiros de roda, todos aproximadamente entre os 20 e 30 anos, quando ele já estava por volta dos 40 .

Talvez seja exatamente por isso e, também, por ter experimentado o fracasso ainda jovem, que Graciliano tenha sido obstinado na segunda vez que investiu em seu projeto literário. Aproximou-se de uma fração da oligarquia política de Alagoas, por meio da qual conseguiu empregos na administração pública local, migrou para Maceió, onde pôde frequentar uma roda intelectual, estabelecendo laços de amizade e sociabilidade literária firmes com seus integrantes, que o auxiliaram tanto na obtenção de editores como na recepção primeira de seus livros, garantindo, assim, num caso e no outro, sua circulação pela capital cultural do país. Se assim fez, foi porque provavelmente sua experiência anterior tenha lhe mostrado que seria necessário cumprir as exigências impostas pelo funcionamento do campo literário brasileiro, que, segundo Randal Johnson (1995), estava em processo de autonomização.
14. “No caso de José

Lins do Rego, [...]

a maior parte dos comentários sobre sua obra saíram pelo Boletim de Ariel, assinados por intelectuais amigos, que trabalhavam como em um sistema de autorreferência" (Sorá, 2010: 137).

Esse tipo de recurso, conforme se depreende do trecho citado, foi mobilizado pela roda de Maceió, podendo-se mesmo falar de estratégias de promoção.

Simone Silva (2004) vai na mesma direção ao analisar as estreias de Mário de Andrade e do próprio José Lins do Rego, privilegiando, nesses casos, o sistema de trocas e obrigações presentes no mundo dos livros. 


\section{Referências}

ARRUDA, Maria Arminda do Nascimento. Modernismo e regionalismo no Brasil: entre inovação e tradição. Tempo Social, v. 23, n. 2, p. 191-212, Nov. 2011.

BOSI, Alfredo. História concisa da literatura brasileira. São Paulo: Cultrix, 2013.

BOURDIEU, Pierre. A economia das trocas simbólicas. São Paulo: Perspectiva, 2013.

As regras da arte: gênese e estrutura do campo literário. São Paulo: Companhia das Letras, 1996.

CANDIDO, Antonio. Formação da literatura brasileira. Rio de Janeiro: Ouro Sobre Azul, 2013.

Ficção e confissão: ensaios sobre Graciliano Ramos. Rio de Janeiro: Ouro Sobre Azul, 2012.

Literatura e sociedade: estudos de teoria e história literária. Rio de Janeiro:

Ouro Sobre Azul, 2011.

A Revolução de 1930 e a cultura. In: A educação pela noite e outros ensaios. São Paulo: Ática, 2000.

CASANOVA, Pascale. A República Mundial das Letras. São Paulo: Estação Liberdade, 2002.

D'ANDREA, Moema Selma. A polêmica revisitada: Regionalismo e Modernismo. Estudos de Sociologia, v. 1, n. 1, p. 53-62, 1995.

ELIAS, Norbert. Mozart: sociologia de um gênio. Rio de Janeiro: Zahar, 1995.

HALLEWELL, Laurence. O livro no Brasil: sua história. São Paulo: Editora USP, 2012.

JOHNSON, Randal. A dinâmica do campo literário brasileiro (1930-1945). Revista USP, n. 26, p. 164-181, Ago. 1995.

LAFETÁ, João Luiz. 1930: a crítica e o Modernismo. São Paulo: Editora 34, 2000.

LEBENSZTAYN, leda. Graciliano Ramos e a novidade: o astrônomo do inferno e os meninos impossíveis. São Paulo: Hedra, 2010.

MENDONÇA, Wellington Pascoal de. A consagração de Graciliano Ramos. Dissertação (Mestrado em Sociologia) - Faculdade de Filosofia, Letras e Ciências Humanas da Universidade de São Paulo, São Paulo, 2018. 
MICELI, Sergio. Intelectuais e classe dirigente no Brasil (1920-1945). In: Intelectuais à brasileira. São Paulo: Companhia das Letras, 2001.

MORAES, Dênis de. O velho Graça: uma biografia de Graciliano Ramos. São Paulo: Boitempo Editorial, 2012.

PONTES, Heloísa. Destinos Mistos: os críticos do Grupo Clima em São Paulo (19401968). São Paulo: Companhia das Letras, 1998.

. Retratos do Brasil: Um estudo dos editores, das editoras e das "Coleções Brasilianas", nas décadas de 1930, 1940 e 1950. Boletim Informativo e Bibliográfico de Ciências Sociais, n. 26, p. 56-89, 1988.

RAMOS, Graciliano. Linhas tortas. Rio de Janeiro: Record, 2015.

Memórias do Cárcere. Rio de Janeiro: Record, 2015.

. Angústia. Rio de Janeiro: Record, 2013.

. Infância. Rio de Janeiro: Record, 2012.

. Cartas. Rio de Janeiro: Record, 2011.

S. Bernardo. Rio de Janeiro: Record, 2010.

. Vidas Secas. Rio de Janeiro: Record, 2005.

. Caetés. Rio de Janeiro: Record, 2000.

ROCHA, Tadeu. Modernismo e regionalismo. Maceió: Edufal, 2014.

SALLA, Thiago Mio; LEBENSZTAYN, leda (Orgs.). Conversas: Graciliano Ramos. Rio de Janeiro: Record, 2014.

SAPIRO, Gisèle. Elementos para uma história do processo de autonomização: o exemplo do campo literário francês. Tempo Social, v. 16, n. 1, p. 93-105, jun. 2004.

SILVA, Simone. As rodas literárias nas décadas de 1920-30: troca e reciprocidade no mundo do livro. Dissertação (Mestrado em Antropologia Social) - Museu Nacional, Universidade Federal do Rio de Janeiro, Rio de Janeiro, 2004.

SORÁ, Gustavo. Brasilianas: José Olympio e a gênese do mercado editorial brasileiro. São Paulo: Editora USP, 2010.

SOUZA, Gilda de Mello e. Teatro ao Sul. In: . Exercícios de leitura. São Paulo: Editora 34, 2008. 
SÜSSEKIND, Flora. Papéis colados. Rio de Janeiro: Editora UFRJ, 2002.

WILLIAMS, Raymond. O Círculo de Bloomsbury. In: - Cultura e materialismo. São Paulo: Editora Unesp, 2011.

Periódicos consultados

Boletim de Ariel. Mensario Critico-Bibliographico. Ano I - Outubro de 1931 a Setembro de 1932. 12 números.

Boletim de Ariel. Mensario Critico-Bibliographico. Ano II - Outubro de 1932 a Setembro de 1933. 12 números.

Boletim de Ariel. Mensario Critico-Bibliographico. Ano III - Outubro de 1933 a Setembro de 1934. 12 números.

Boletim de Ariel. Mensario Critico-Bibliographico. Ano IV - Outubro de 1934 a Setembro de 1935. 12 números.

Boletim de Ariel. Mensario Critico-Bibliographico. Ano V - Outubro de 1935 a Setembro de 1936. 12 números.

Arquivos consultados

Arquivo IEB-USP, Fundo Graciliano Ramos, Coleção Correspondência Ativa.

Arquivo IEB-USP, Fundo Graciliano Ramos, Coleção Correspondência Passiva.

Arquivo IEB-USP, Fundo Graciliano Ramos, Coleção Correspondência entre Terceiros. 